Artigos

Volume 9 - 2019| n. 23

\title{
A Utilização de Sistemas Privados de Ensino na Educação Pública: o divórcio entre a teoria e a prática nas políticas educacionais
}

\author{
Elisandra Aparecida Czekalski \\ Marisa Schneckenberg \\ Universidade Estadual do Centro Oeste (UNICENTRO), Guarapuava/PR - Brasil
}

\section{Resumo}

O presente trabalho pretende discutir a relação entre a concepção de infância e de currículo descritos nos documentos municipais que orientam o currículo de um município situado na região Sudeste do estado do Paraná versus o modo como esse mesmo município conduz sua ação educativa frente a essas concepções. Arguimos tal questão dado o fato de que a rede municipal pesquisada destina apostilas do sistema privado de ensino às crianças da Educação Infantil. Em consequência disso, pressupõe-se que essa escolha deva constar em suas normativas curriculares, fundamentando a decisão. As contradições averiguadas nos textos municipais denotam o reflexo de uma sociedade regulada por preceitos neoliberais, que objetivam a privatização da Educação. A ação consciente e transformação social tão enfatizada na Proposta Curricular Municipal são ações que a política pública municipal não faz questão de assegurar, promovendo cada vez mais a reprodução cultural da classe dominante.

Palavras-chave: Sistemas Privados de Ensino. Proposta Curricular Municipal. Projeto Político Pedagógico. Educação Infantil.

\section{The Use of Private Education Systems in Public Education: the divorce between theory and practice in educational policies}

\begin{abstract}
The present study aims to discuss the relationship between the conception of childhood and of curriculum described in the municipal documents that guide the Curricular Proposal of a municipality situated in the Southeast region of the State of Paraná, Brazil, versus the way how this municipality conducts its educational actions in face of these conceptions. This subject was selected due to the fact that the Education department of the municipality under research designates private education system workbooks to the children of Early Childhood Education. As a consequence, it is assumed that this choice should be included in its curricular regulations, in order to justify this decision. The contradictions verified in the municipal texts denote the reflection of a society regulated by neoliberal precepts, which aim at the privatization of education. The conscious action and social transformation which is so emphasized in the Municipal Curricular Proposal are actions that the municipal public policy is not invested in assuring, promoting more and more the cultural reproduction of the dominant class.
\end{abstract}

Keywords: Private Education Systems. Municipal Curricular Proposal. Political Pedagogical Project. Early Childhood Education. 
A Utilização de Sistemas Privados de Ensino na Educação Pública

\section{Introdução}

Este trabalho discute a relação entre a concepção de infância e de currículo descritos nos documentos que orientam o currículo de um município situado na região Sudeste do estado do Paraná versus o modo como esse mesmo município conduz sua ação educativa frente a essas concepções. Em outras palavras, indagamos se o discurso que tais documentos proferem condiz com a realidade e se o que está descrito na teoria é o que ocorre na prática? Tal questão é suscitada em virtude de a rede municipal pesquisada utilizar material didático (apostilas) do sistema privado de ensino, sendo destinado às crianças da Educação Infantil e Anos Iniciais do Ensino Fundamental. Em consequência disso, pressupõe-se que essa escolha deva constar descrita em suas normativas curriculares, fundamentando a decisão.

Destaca-se que o presente trabalho se trata de um recorte de estudos na pós-graduação stricto sensu, que tem como escopo discutir a parceria entre o setor público e privado na adoção de material apostilado para a Educação Infantil dos Centros Municipais de Educação Infantil (CMEI).

A descoberta do sentimento de infância, de certa maneira, culminou na ideia da necessidade de educá-la, sendo necessário, para isso, criar dispositivos, lugares, materiais e metodologias. Mas essas formas seriam as mais adequadas? Sobre que infância se pensava? Por que criar um currículo? Que currículo? Para que infância?

As políticas públicas definiram, ao longo da trajetória de construção da Educação Infantil, diretrizes referenciais que são amparadas em uma base comum nacional. Esta deverá ser complementada pelas particularidades do contexto local e da integração de experiências no intento de somar ao que já está previsto na base. Nesse modo de complementação e integração, somos levados a indagar sobre um fator comum que ocorre nos espaços que acolhem a Educação Infantil municipal: o uso de apostilas do setor privado.

Posto isso, o presente trabalho organiza-se em três momentos. No primeiro, discute-se os documentos, legislação e orientações que estabelecem e orientam o currículo para a Educação Infantil em nível local, assim como fundamentam a organização do trabalho pedagógico nas escolas do município investigado, quais sejam: a Proposta Curricular Municipal e o Projeto Político Pedagógico dos CMEI (s. d.) ${ }^{1}$. Em um segundo momento, é realizada uma breve leitura da proposta de atividades presentes na apostila utilizada pelas crianças de três anos. No terceiro momento, delineia-se a relação entre o discurso dos documentos versus a prática efetivada no interior dos CMEI municipais.

\section{A Proposta Curricular da Rede Municipal de Ensino para a Educação Infantil}

É relevante observar que a Educação Infantil, como política pública de caráter educativo e não meramente assistencialista, no município investigado, é recente, pois foi somente a partir da Lei Municipal № 2806/2008 que a primeira infância passou a construir sua identidade. Nesse contexto, os profissionais que ali trabalhavam, antes denominados de monitores de

1 Cabe ressaltar que o município se encontra em um momento de reestruturação da Proposta Curricular Municipal e dos PPP; assim, os dados aqui dispostos podem vir a sofrer modificações no decorrer do tempo. 
A Utilização de Sistemas Privados de Ensino na Educação Pública

creche, passaram a ser considerados professores. A rotina, que apresentava aspectos somente de cuidado e guarda, passa a propor caráter educacional e pedagógico. Com isso, abre-se espaço tanto para concurso público específico para o cargo de professor de Educação Infantil assim como para a construção da Proposta Curricular para a Educação Infantil da Rede Municipal de Ensino.

A adoção de sistema apostilado de ensino pelo município é um verdadeiro quebracabeça. Para melhor compreensão de como ocorreu essa parceria cabe destacarmos uma breve linha do tempo das gestões municipais, do órgão municipal responsável pela gestão da Educação Infantil, da editora contratada e das turmas que receberam as apostilas.

Quadro 1 - Linha histórica da parceria

\begin{tabular}{|c|c|c|}
\hline $\begin{array}{c}\text { Gestão/Período/ } \\
\text { Coligação } \\
\text { Partidária }{ }^{2}\end{array}$ & $\begin{array}{c}\text { Órgão/Secretaria responsável pela Educação Infantil- } \\
\text { Fatos históricos- Editora contratada }\end{array}$ & $\begin{array}{c}\text { Turmas/Séries que } \\
\text { utilizavam as } \\
\text { apostilas }\end{array}$ \\
\hline $\begin{array}{l}2001-2004 \\
\text { PSDB-PTB }\end{array}$ & $\begin{array}{l}\text { PROVOPAR responsável pelas creches - Em } 2001 \text { se dá } \\
\text { início da parceria entre a Prefeitura Municipal e Editora BASE. }\end{array}$ & $\begin{array}{l}\text { Educação Infantil e } \\
\text { Ensino Fundamental. }\end{array}$ \\
\hline $\begin{array}{l}2005-2008 \\
\text { PPS-PSB }\end{array}$ & $\begin{array}{l}\text { Até } 2007 \text { PROVOPAR, em } 2008 \text { inicia-se a transição de } \\
\text { responsabilidade para a Secretaria Municipal de Educação. }\end{array}$ & Educação Infantil. \\
\hline $\begin{array}{l}2009-2012 \\
\text { PPS-PSB }\end{array}$ & $\begin{array}{l}\text { Em } 2009 \text { ocorre o primeiro concurso para Professor de } \\
\text { Educação Infantil no município. Em } 2011 \text { é elaborada a PCEI. } \\
\text { A Editora BASE muda de nomenclatura passa a ser Editora } \\
\text { SEFE (Sistema Educacional Família Escola). }\end{array}$ & Educação Infantil. \\
\hline $\begin{array}{l}\text { 2013-2016 } \\
\text { PT }\end{array}$ & $\begin{array}{l}\text { Em } 2016 \text { inicia-se no município a obrigatoriedade de matrícula } \\
\text { das crianças de } 4 \text { anos, e transferência das crianças dos CMEl } \\
\text { para as escolas municipais. Iniciam-se discussões para } \\
\text { reformulação da PCEl. }\end{array}$ & $\begin{array}{l}\text { Educação Infantil e } \\
\text { Séries iniciais do } \\
\text { Ensino Fundamental. }\end{array}$ \\
\hline $\begin{array}{l}2017-2020 \\
\text { PSDB }\end{array}$ & $\begin{array}{l}\text { Quatro anos de vigência do Plano Municipal de Educação, e a } \\
\text { prospecção de atendimento de } 50 \% \text { de crianças de } 0 \text { a } 3 \text { anos } \\
\text { nos CMEl's ainda não se concretiza. Iniciam-se discussões } \\
\text { para reformulação dos PPP dos CMEI. A Editora SEFE se une } \\
\text { à outra editora, a OPET, ficando nomeada de OPET/SEFE. }\end{array}$ & $\begin{array}{l}2017 \text { e } 2018 \text { = } \\
\text { Educação Infantil e } \\
\text { Séries iniciais do } \\
\text { Ensino Fundamental } \\
\text { Em } 2019 \text { voltou a ser } \\
\text { utilizado somente pela } \\
\text { Educação Infantil. }\end{array}$ \\
\hline
\end{tabular}

Fonte: Elaborado pelas autoras com base em dados obtidos durante a pesquisa.

Através desses dados constata-se que a implementação da parceria se deu no ano de 2001. Nessa data, a gestão da Educação Infantil era de responsabilidade do PROVOPAR, a Secretaria Municipal de Educação assume essa incumbência somente no ano de 2008, ou seja, sete anos depois do início da parceria. Desse modo, mesmo a Educação Infantil não sendo de responsabilidade da Secretaria Municipal de Educação em 2001, as crianças que frequentavam as creches na época já faziam o uso de apostilas.

Quanto à construção da Proposta Curricular Municipal para a Educação Infantil, esta ocorre somente em 2011, dez anos após a implementação da parceria. O que nos sugere a indagação sobre o porquê de as crianças serem atendidas nas creches, as quais não possuíam proposta curricular estabelecida ou específica, pois pertenciam a um órgão municipal de cunho assistencialista e utilizavam material apostilado de um sistema privado de ensino.

Outra característica destes 18 anos de parceria é de que esta ora atende a Educação Infantil e Ensino Fundamental, ora somente a Educação Infantil. No que concerne às

2 Elaborado pelas autoras com base em dados disponíveis na Prefeitura Municipal e Câmara de Vereadores do município pesquisado. 
A Utilização de Sistemas Privados de Ensino na Educação Pública

discussões para a reformulação da Proposta Curricular para a Educação Infantil (PCEI), foram até o momento feito alterações somente nos conteúdos, as bases teórico-pedagógica, filosófica e psicológica permanecem as mesmas, porém, são seis anos de discussões e não houve qualquer encaminhamento. Percebemos ainda que, nos 18 anos de parceria, ao menos quatro coligações partidárias diferentes assumiram as gestões municipais, no entanto, o contrato com a Editora responsável pela edição do conteúdo, que por sua vez só sofreu mudanças de nomenclatura, prosseguiu.

A Proposta Curricular para a Educação Infantil, organizada no ano de 2011, ensejava que o currículo para a infância estivesse "[...] centrado nas áreas de conhecimento e deverá contribuir para a prática e vivência pedagógicas plenas de êxito, prazer e alegria, culminando com aprendizagem satisfatória e significativa das crianças" (IRATI, 2011, p. 09).

Para que ocorra este aprendizado significativo,

[...] a escola não pode limitar-se somente a oferecer aos alunos algumas noções de diversos ramos do saber, mas sim, contribuir com a formação da consciência deste educando [...], porém, para isso é necessário que esta instituição realize sua tarefa oferecendo um ensino de qualidade, resistindo ao modismo, fundamentando-se em teorias que vão além da preparação para o trabalho (IRATI, 2011, p. 17,19).

Diante disso, a referida proposta adota, como linhas norteadoras de sua prática pedagógica, o Materialismo Histórico, a Psicologia Histórico-cultural e a Pedagogia Históricocrítica (SAVIANI, 1989). Portanto, essa Proposta Curricular acredita "[...] que seguindo esta linha de pensamento é possível à escola organizar um processo de apropriação do saber, o qual venha a atender as necessidades dos educandos, contribuindo para a formação da consciência humana" (IRATI, 2011, p. 22).

Esse processo de trabalho pedagógico provém da concepção dialética do conhecimento, a qual perpassa três fases distintamente correlacionadas: prática-teoriaprática. Assim, parte-se "[...] do nível de desenvolvimento atual dos alunos, trabalhando na zona de seu desenvolvimento imediato, para chegar a um novo nível de desenvolvimento atual, conforme a Teoria Histórico Cultural, de Vigotski ${ }^{\prime \prime}$ (GASPARIN, 2012, p. 08).

Dessa forma, o trabalho pedagógico, a partir da perspectiva da Pedagogia Históricocrítica, prevê que sejam superados, dentro dos espaços educativos, nas práticas pedagógicas dos docentes, aspectos que deem ênfase a atividades aleatórias, fora de contexto, imitativas, cópia, repetição, e sem intencionalidade, pois é a partir dessa superação que a escola assumirá sua "função de espaço de apropriação do saber" (IRATI, 2011, p. 23).

A concepção de criança adotada pelo documento é a de "[...] um ser social que tem sua história de vida e precisa de experiência de um professor comprometido que atue como mediador para promover a elevação como homem dando-lhe uma identidade social e cultural" (IRATI, 2011, p. 24).

Essa mediação ocorrerá por meio da interação social, "[...] daí decorre um método pedagógico que parte da prática social onde professor e aluno se encontram igualmente inseridos, ocupando, porém, posições distintas" (SAVIANI, 1989, p. 36). Nesse processo de interação, a criança não é tida como uma página em branco que necessita ser preenchida, mas uma página que já possui elementos de conhecimento construídos, que, a partir do

3 Ver Vigotski (2001). 
A Utilização de Sistemas Privados de Ensino na Educacão Pública

processo de mediação/interação, tenderão a aumentar. Dessa forma, a cada nova interação/mediação, a página agregará novos elementos. "O conhecimento sistematizado, neste processo de unidade e luta, nega, incorpora e supera o conhecimento existente, gerando um todo novo de nível superior" (GASPARIN, 2012, p. 07).

Para isso, a Proposta Curricular Municipal da cidade investigada, norteada pela Pedagogia Histórico-crítica,

[...] organiza seu currículo em áreas do conhecimento [...] oferecendo: atividades contextualizadas, diversidade de recursos, problematização dos conteúdos, formação constante do professor, ênfase na aprendizagem dos alunos e reconhecendo o conhecimento científico como eixo norteador das atividades pedagógicas (IRATI, 2011, p. 37).

O conteúdo de cada área do conhecimento é desenvolvido no planejamento do professor, considerando os aspectos da Pedagogia Histórico-crítica (PHC) de Gasparin (2012), que contempla cinco passos: prática social inicial, problematização, instrumentalização, catarse e prática social final. Desse modo, este

[...] processo pedagógico deve possibilitar aos educandos, através do processo de abstração, a compreensão da essência dos conteúdos a serem estudados, a fim de que sejam estabelecidas as ligações internas específicas desses conteúdos com a realidade global, com a totalidade da prática social e histórica [...] a teorização possibilita, então, passar do senso comum particular, como única explicação da realidade, para os conceitos científicos e juízos universais que permitem a compreensão dessa realidade em todas as suas dimensões (GASPARIN, 2012, p. 06).

A prática social inicial é o primeiro passo do desenvolvimento do planejamento da PHC. Esse momento caracteriza-se por "[...] uma mobilização do aluno para a construção do conhecimento escolar. É uma primeira leitura da realidade, um contato inicial com o que tem a ser estudado" (GASPARIN, 2012, p. 13). Desse modo não há, necessariamente, um momento no qual o docente deve conhecer seu aluno na íntegra, mas "[...] respeitar os diferentes níveis de conhecimento que o aluno traz consigo à escola. [...] O educador deve considerar essa leitura do mundo inicial que o aluno traz consigo, ou melhor, em si" (FREIRE; CAMPOS, 1991 apud GASPARIN, 2012, p. 14).

Tomando como ponto de partida o conhecimento e a leitura de mundo prévia dos alunos, o professor deverá realizar com eles um diálogo, a fim de "verificar que domínio já possuem e que uso fazem dele na prática social cotidiana" (GASPARIN, 2012, p. 20). O processo de diálogo configura-se em um espaço de interação e confiança entre os pares, com vistas à superação do estereótipo da educação bancária. Desse ponto em diante, cabe ao professor pautar "[...] de onde deve iniciar sua ação e o que falta ao aluno para chegar ao nível superior, expresso pelos objetivos, os quais indicam a meta a ser atingida" (GASPARIN, 2012, p. 21).

O segundo passo da proposta da PHC é a problematização, sendo "[...] um elemento chave na transição entre prática e teoria, isto é, entre o fazer cotidiano e a cultura elaborada. É o momento em que se inicia o trabalho com o conteúdo sistematizado" (GASPARIN, 2012, p. 33). Nesse sentido, a problematização considera todos os possíveis questionamentos acerca de determinado conteúdo, e que ele não é somente resultado de um conhecimento científico, mas "[...] um produto social, nascido de necessidades históricas, econômicas, políticas, ideológicas, filosóficas, religiosas, técnicas etc. Todo conteúdo, portanto, reveste-se 
A Utilização de Sistemas Privados de Ensino na Educacão Pública

dessas dimensões, as quais devem ser tratadas juntamente com a dimensão dita científica" (GASPARIN, 2012, p. 38).

Dessa forma, são elencados questionamentos em cada uma das dimensões descritas, para cada conteúdo que será trabalhado dentro de cada área específica do conhecimento. Isso exige, do professor, "[...] uma nova maneira de estudar e preparar o que será trabalhado com os alunos: o conteúdo é submetido a dimensões e questionamentos que exigem do mestre uma reestruturação do conhecimento que já domina" (GASPARIN, 2012, p. 46).

Ademais, é possível, ainda, que os próprios alunos levantem outros questionamentos, fomentando a busca do professor por mais respostas para suas dúvidas. Nesse sentido, "a aprendizagem assume, gradativamente, um significado subjetivo e social para o sujeito aprendente" (GASPARIN, 2012, p. 47). Todos os questionamentos realizados no processo de problematização serão respondidos no terceiro item da proposta da PHC, a instrumentalização. Isso porque ela

[...] é o caminho pelo qual o conteúdo sistematizado é posto à disposição dos alunos para que o assimilem e o recriem e, ao incorporá-lo, transformam-no em instrumento de construção pessoal e profissional. [...] Em virtude disso, os educandos, com auxílio e orientação do professor, apropriam-se do conhecimento socialmente produzido e sistematizado para enfrentar e responder aos problemas levantados (GASPARIN, 2012, p. 51).

Nesse processo, cabe ao professor apresentar o conteúdo em suas dimensões e contrastá-lo com o conhecimento prévio do aluno. Assim, os discentes, ao apropriarem-se desses novos conceitos, elevam seu conhecimento. "Todo esse processo se desenvolve intencionalmente, pelos procedimentos adequados, cuja finalidade é a construção/reconstrução do conhecimento sistematizado. O professor, nesse caso, atua como mediador entre o aluno e o objeto do conhecimento" (GASPARIN, 2012, p. 105). Portanto, "[...] a fase da Instrumentalização é o centro do processo pedagógico. É nela que se realiza, efetivamente a aprendizagem (GASPARIN, 2012, p. 122).

Posterior ao processo de análise, no percurso da instrumentalização, decorre o quarto passo da proposta da PHC, a catarse, que é

[...] a síntese do cotidiano e do científico, do teórico e do prático a que o educando chegou, marcando sua nova posição em relação ao conteúdo e à forma de sua construção social e sua reconstrução na escola. [...] é a conclusão, o resumo que ele faz do conteúdo aprendido recentemente. É o novo ponto teórico de chegada; a manifestação do novo conceito adquirido (GASPARIN, 2012, p. 124).

É nesse momento que se apresentam as novas posturas cognitivas do aluno frente a determinado conteúdo. Isso fica claro no modo como o educando se posiciona diante desse novo contexto, que, de fato, é distinto do qual se apresentava no início do processo, na prática social inicial. "É a conclusão de todo um trabalho" (GASPARIN, 2012, p. 129).

Entretanto, ele não é definitivamente o final. Essa finalização retorna ao seu estágio inicial, ou seja, para a prática social final.

Esta fase representa a transposição do teórico para o prático dos objetivos da unidade de estudo, das dimensões do conteúdo e dos conceitos adquiridos. [...] esse processo de compreensão do conteúdo ainda não se concretizou como prática. Esta exige uma ação real do sujeito que aprendeu, requer uma aplicação (GASPARIN, 2012, p. 139-140). 
A Utilização de Sistemas Privados de Ensino na Educacão Pública

Esse seria o ápice do processo de aprendizagem pela proposta da $\mathrm{PHC}$, seria o momento em que o aluno compreende de nova forma a realidade e de como se posiciona frente a ela. "É a manifestação da nova postura, da nova atitude, da nova visão do conteúdo no cotidiano. É, ao mesmo tempo, o momento da ação consciente, na perspectiva da transformação social, retornando à Prática Social Inicial, agora modificada pela aprendizagem" (GASPARIN, 2012, p. 143).

Nesse contexto, indagamos: o uso de apostilas por crianças pequenas incidiria possibilidades para a construção da ação consciente e perspectivas de transformação social?

$\mathrm{Na}$ sequência, vemos como é a autonomia escolar do município investigado, no que concerne ao currículo nas instituições de Educação Infantil perante a composição de seus Projetos Políticos Pedagógicos.

\section{O currículo nos Projetos Político Pedagógicos dos Centros Municipais de Educação Infantil}

O Projeto Político Pedagógico (PPP) consiste em um documento que expressa a identidade e autonomia de uma unidade escolar. Veiga (2002) alega que sua construção parte dos princípios de igualdade, qualidade, liberdade, gestão democrática e valorização do magistério. Desse modo, ao pensar o PPP de nossas instituições escolares, inevitavelmente pensamos, junto com ele, as intenções futuras que temos para com esses princípios. Com isso,

Projetar significa tentar quebrar um estado confortável para arriscar-se, atravessar um período de instabilidade e buscar uma nova estabilidade em função da promessa que cada projeto contém de estado melhor do que o presente. Um projeto educativo pode ser tomado como promessa frente a determinadas rupturas. As promessas tornam visíveis os campos de ação possível, comprometendo seus atores e autores (GADOTTI, 1994, p. 579).

Diante disso, ponderamos que o PPP deve ser algo muito maior do que a união de textos que foram organizados com vistas a cumprir determinada função burocrática. Ele deve ser parte constitutiva da realidade cotidiana da comunidade escolar. Para tanto, "[...] a construção de um projeto político pedagógico com motivação fundamentalmente burocrática tem prevalecido sobre práticas que o reconhecem como importante caminho para a elevação da autonomia da escola" (CARIA, 2011, p. 18).

Foi essa a realidade encontrada durante a averiguação dos PPP dos CMEI do munícipio pesquisado. Verificou-se que esses documentos são iguais, nas doze instituições que abrigam a Educação Infantil Municipal, assim como o fato de a comunidade escolar não ter tido participação ativa em sua elaboração. Desse modo, as concepções acerca de criança e currículo não consideram a identidade particular de cada escola, mas as caracterizam em aspectos amplos e comuns para todas as unidades escolares.

Entendemos que no município, tendo como base para sua proposta curricular a PHC, os documentos das instituições escolares seguirão essa mesma linha. Porém, é imprescindível que cada escola, na construção do PPP, traduza suas devidas características, dando sentido e identidade própria a esse documento.

Faz-se necessário reforçar que os PPP traduzem a concepção de criança tal qual "[...] todo ser humano é um sujeito social e histórico e faz parte de uma organização familiar que 
A Utilização de Sistemas Privados de Ensino na Educacão Pública

está em uma sociedade, a qual possui uma determinada cultura em um determinado momento histórico" (IRATI, s. d.) $)^{4}$.

Estando assentada na concepção Histórico-cultural do sujeito, os CMEI organizam seu currículo em conteúdos por área de conhecimento, seguindo uma organização por meio de uma "rotina estável, clara e compreensível" (IRATI, s. d.). A rotina compreende proporcionar às crianças atividades alternativas, de livre escolha, coletivas e físicas.

Desse modo, segundo os PPP municipais, as atividades alternativas são atividades propostas "em função do interesse das crianças por algum fato, objeto ou acontecimento", as quais, geralmente, são oferecidas ao grupo coletivo, sendo realizadas tanto em sala de aula como em outros espaços dos CMEl. Deduz-se, por essa proposta, que o trabalho aqui é bastante aberto à vontade e curiosidade das crianças, praticando, por parte do docente, a escuta, pois ela "[...] é uma possibilidade dos adultos perceberem e tornarem-se conscientes das tantas riquezas e potencialidades das crianças" (MALAGUZZI apud FOCHI, 2014, p. 15).

Logo, é imprescindível que os adultos proporcionem meios e aprendam a dar voz à infância, pois,

[...] se não aprendermos a escutar as crianças, será difícil aprender a arte de estar e conversar com elas (de conversar em um sentido físico, formal, ético e simbólico). Será também difícil, acaso impossível, compreender como e porque pensam e falam as crianças; compreender o que fazem, pedem, planejam, teorizam ou desejam; compreender qual mensagem preferem, quais procedimentos exploram ou elegem para influenciar seu entorno ou obter conhecimento (HOYUELOS apud FOCHI, 2014, p. 15-16).

As atividades de livre escolha são aquelas que "[...] podemos oferecer para que as crianças escolham o que desejam fazer e deem oportunidade à realização de trabalhos mais individualizados" (IRATI, s. d.). Nesse sentido, as "crianças podem agir individualmente aprendendo a se desenvolver de forma autônoma, sem perder de vista a relação com o grupo" (FOCHI, 2014, p. 16).

As atividades coletivas são organizadas e propostas pelos docentes às crianças, e buscam trabalhar a interação entre os pares, assim como a atenção e a concentração. Destacam-se, dentre essas atividades: "jogos sensoriais, brincadeiras e rodas cantadas, audição de histórias, conversas na roda" (IRATI, s. d.). É durante as atividades em grupos que ocorrem a interação e troca. Essa "troca entre os pares, os semelhantes e os diferentes enriquece o grupo e o sujeito" (FOCHI, 2014, p. 16).

Já as atividades físicas são realizadas cotidianamente e buscam tornar a criança menos dependente do adulto, pois

São atividades que se caracterizam pelo cuidado, mas que também tem seu caráter educativo, como sentar à mesa com colegas e professora para as refeições, repartir o que tem para comer, esperar sua vez para ser servido, limpar seu lugar de trabalho e alimentação, ir ao banheiro sem auxílio do adulto, realizar sua higiene com independência (IRATI, s. d.).

\footnotetext{
4 O ano e paginação dos PPP estão suprimidos da referência, uma vez que todos os PPP são iguais; porém, o ano e suas readequações são diferentes, assim como a paginação difere por conta da formatação que cada documento possui.
} 
A Utilização de Sistemas Privados de Ensino na Educação Pública

Pontuamos que as atividades físicas descritas nos PPP dão ênfase às atividades físicas como domínio dos corpos, do autocuidado e promoção da autonomia. Porém, não as descrevem como fator determinante no desenvolvimento das crianças e que, como componente do currículo, devem objetivar, no aluno, a "[...] cultura corporal de movimento, formando o cidadão que vai produzi-la, reproduzi-la e transformá-la, instrumentalizando-o para usufruir do jogo, do esporte, das atividades rítmicas e dança, das ginásticas e práticas de aptidão física, em benefício da qualidade de vida" (BETTI; ZULIANI, 2002, p. 75). Nesse aspecto, a construção do PPP, ao abordar as questões físicas e/ou corporais, não pode incorrer na proposição de um discurso que derrube a riqueza de suas especificidades.

Os PPP apresentam, ainda, algumas sugestões de cantos fixos e alternativos para as atividades das crianças. Os cantos fixos podem ser organizados a partir de determinada temática fixa: cantos da fantasia, da biblioteca, da garagem, dos jogos, brinquedos, etc. Já os cantos alternativos podem variar conforme os temas que estão sendo trabalhados.

Em relação aos conteúdos a serem trabalhados com as crianças, estão expostos na PCEl em tabelas, divididos por bimestres e idade específica das crianças, conforme demonstramos neste pequeno recorte do documento, dos conteúdos da disciplina de Matemática para a turma do Maternal I (crianças com 2 anos de idade).

Quadro 2 - Exemplos de conteúdo de matemática para crianças do Maternal I

\begin{tabular}{|l|l|l|l|l|}
\hline Período letivo & $1^{\circ}$ BIMESTRE & $2^{\circ}$ BIMESTRE & $3^{\circ}$ BIMESTRE & $4^{\circ}$ BIMESTRE \\
\hline & Agrupamentos: cor & Agrupamentos: & Classificação, & Agrupamentos: \\
& e formas; & cor e formas; & seriação, número; & cor, forma; \\
& $\begin{array}{l}\text { Contagem oral; } \\
\text { Noção de } \\
\text { quantidade e } \\
\text { tamanho. }\end{array}$ & $\begin{array}{l}\text { Contagem oral; } \\
\text { quano de } \\
\text { quantidade e } \\
\text { tamanho. }\end{array}$ & $\begin{array}{l}\text { Geometria; } \\
\text { Círculo. }\end{array}$ & $\begin{array}{l}\text { Noção de } \\
\text { quantidade e } \\
\text { tamanho. }\end{array}$ \\
\hline
\end{tabular}

Fonte: Elaborado pelas autoras com base na PCEI (2011).

É importante destacarmos que o documento da PCEI data do ano de 2011, ou seja, sua elaboração ocorre após a aprovação das Diretrizes Curriculares Nacionais para a Educação Infantil (DCNEI). Assim, a configuração da proposta curricular municipal, ao estabelecer conteúdos por bimestres, contrapõe-se inteiramente às orientações dadas pelas Diretrizes, uma vez que estas pressupõem que a ação pedagógica com as crianças deve ser essencialmente lúdica, prazerosa, com ênfase às atividades que contemplem o uso dos sentidos, da experimentação, das vivências, possibilitando, assim, o desenvolvimento integral das crianças.

\section{A proposta curricular da Editora: as atividades na apostila para crianças de 3 anos}

Mesmo não sendo o foco principal deste trabalho a análise do conteúdo das apostilas utilizadas pelas crianças, não poderíamos deixar de realizar alguns apontamentos sobre esse material. Em leitura acerca da proposta curricular da Editora OPET/SEFE, para a rede pública de ensino ${ }^{5}$, destaca-se que esta segue como fundamento teórico na organização das atividades propostas "a concepção histórico-cultural da educação" (ENTRELINHAS..., 2017, p. 13).

5 A Editora OPET/SEFE oferece material diferenciado para escolas da rede particular e da rede pública. 
A Utilização de Sistemas Privados de Ensino na Educação Pública

Conforme informações no material, a coleção Entrelinhas para você está dividida por faixa etária, sendo ofertado dois livros anuais para crianças de três anos. A apostila do primeiro semestre vem com 100 páginas de atividades e, a do segundo semestre, conta com 86 páginas.

Ressaltamos que, dentro do calendário escolar municipal, o primeiro semestre conta com um total de 101 dias letivos e, o segundo semestre, com um total de 99 dias letivos. Se analisarmos a quantidade de dias letivos em relação à quantidade de páginas que cada apostila contém durante o semestre, logo concluímos que ao menos uma página tenha de ser feita ao dia para que ao final do semestre o material não seja entregue em branco. Lembramos, ainda, que as professoras devem desenvolver seus planejamentos bimestrais elencando os conteúdos propostos pela PCEI.

Ainda consta que o material está organizado em consonância com a Base Nacional Comum Curricular (BNCC). Cada volume é composto por núcleos que, "[...] apresentam diversas experiências de aprendizagem de acordo com os campos que foram definidos para a coleção, considerando todos os aspectos de desenvolvimento da criança postos nas DCNEI" (ENTRELINHAS..., 2017, p. 23).

As DCNEI, em seu artigo $9^{\circ}$, inciso I asseveram que,

As práticas pedagógicas que compõem a proposta curricular da Educação Infantil devem ter eixos norteadores as interações e a brincadeira, garantindo experiências que: I promovam o conhecimento de si e do mundo por meio da ampliação de experiências sensoriais, expressivas, corporais que possibilitem movimentação ampla, expressão da individualidade e respeito pelos ritmos e desejos da criança (BRASIL, 2009a, p. 21, grifo nosso).

Porém, em uma breve análise das atividades propostas em um dos núcleos da apostila Entrelinhas para você para crianças de três anos, pudemos verificar que as atividades se baseiam sempre num mesmo direcionamento, observações e o registro em desenho. Pegamos como exemplo o núcleo 2, denominado de Interações e experiências na escola. No início das orientações o material do professor expõe que esse núcleo:

Tem a intenção de promover uma melhor familiaridade das crianças com os espaços da instituição de educação infantil. É necessário que elas conheçam também todos os adultos que as acompanham para se sentirem mais seguras. Por meio da interação entre crianças, seus colegas, os demais grupos e funcionários da instituição, elas vão refletir sobre a boa convivência, além de brincar e se divertir muito (ENTRELINHAS..., 2017, p. 60).

Porém, a sequência de atividades sugeridas e impressas no material do aluno resumese a observações, pintura em guache e registro em desenho. Descreveremos sucintamente a sequência das atividades propostas nesse núcleo. Nas páginas 22 e 23 há ilustrações com as seguintes situações, crianças no piquenique, brincando em sala, em uma mini-horta, e é solicitado que as crianças as observem e tirem suas conclusões. A página 24 pede que as crianças observem sua sala de aula de diversos ângulos e posições e ilustrem em desenho o que observaram. A página 25 convida a fazer um passeio por todos os ambientes da escola e novamente registrar por meio de desenho suas percepções. Na página 26 a atividade pede que as crianças por meio de desenho representem algumas pessoas que convivem com elas na escola. A página 27 aborda as regras nos ambientes, e pede que depois de diálogo 
A Utilização de Sistemas Privados de Ensino na Educacão Pública

representem em desenho qual regra da sala foi elaborada por eles. A página 28 traz um ligue cada objeto ao seu devido lugar, como livros na sala de aula, baldinho e pazinha no parque de areia. A página 29 pede que se usem diversos objetos para se fazer carimbos em tinta guache.

A página 30 pede que montem uma lupa do encarte (que se encontra no final da apostila) com papel celofane a fim de observarem as cores e suas possibilidades. A página 31 propõe que se realize um passeio pela escola e se registre por meio de desenho objetos de cheiros agradáveis que encontrarem no passeio. A página 33 solicita que, com a ajuda da professora, façam um aromatizador de ambientes, a página 34 solicita que destaquem do encarte as peças que faltam de algumas frutas. A página 35 traz a obra de Aracy (coleção particular), Brincadeira de criança, para observação e relato de quais brincadeiras gostam. Finalizando o núcleo 2, na página 35 há a canção vamos brincar de roda, com ilustração gráfica (desenho), e se pede que as crianças destaquem do encarte as peças que faltam e completem a gravura.

Observamos que, da página 24 até a 27 e a 31 , as atividades se resumem em observações e seu registro em desenhos. As que conotam certa experiência são as atividades das páginas 29 e 33. As demais não são desafiadoras, não agregam o que preconiza as $\mathrm{DCNEI}$, que seriam as interações e brincadeiras, não trabalham aspectos de movimento, expressividade, ludicidade, nem ampliam experiências sensoriais.

Dessa maneira, fica explícita a pobreza de diversidade nas atividades propostas em quatorze páginas da apostila que é oferecida às crianças de três anos de idade. Crianças totalmente ativas, curiosas, que requerem estar em constante movimento, de manter contato com o outro, com o mundo externo, com a natureza.

Essa rotina uniforme de cunho escolarizado tende a se tornar um ato de "[...] dominação quando não considera o ritmo, a participação, a relação com o mundo, a realização da fruição, a liberdade, a consciência, a imaginação e as diversas formas de sociabilidade dos sujeitos nela envolvidos" (BARBOSA, 2001, p. 96). Parece ser muito mais fácil padronizar o trabalho com as crianças do que lhes dar autonomia para que construam, inventem, experimentem, manifestem suas predileções ao que podem fazer, construir, experimentar, aprender.

O que vemos cada vez mais é a Educação Infantil emparedada, com atividades maçantes, homogêneas, muitas vezes até sem sentido às crianças. Esse emparedamento da infância contribui na subtração de possibilidades de as crianças viverem grandes e significativas experiências.

\section{O divórcio entre a teoria e a prática nas políticas educacionais: conclusões finais}

Verificamos que os documentos municipais asseveram um trabalho pautado em uma perspectiva que leva em consideração o sujeito, seu contexto social, a interação dele com o outro, detalhada em uma didática da PHC, na qual as problematizações são o escopo principal de ensino. Vale ressaltar que, nesse procedimento apresentado pela proposta da PHC, por mais que leve em consideração o conhecimento prévio do aluno sobre determinada questão, há, anteriormente a essa consideração, toda uma listagem de conteúdo já preconcebida na Proposta Curricular Municipal. 
A Utilização de Sistemas Privados de Ensino na Educação Pública

Observa-se, ainda, conforme quadro histórico no que se refere ao período da gestão municipal e de suas ações, que a implantação do sistema apostilado ocorre em 2001, ou seja, dez anos antes da instituição da PCEl, período em que a Educação Infantil era de responsabilidade da assistência social (PROVOPAR). A transição começa a ocorrer somente em 2008. Desse modo, a incoerência se agrava, pois a postura da gestão municipal diante da instituição da PCEI (2011), regida e pautada pela PHC, que tem como foco o sujeito e seu contexto social, acaba por desconsiderá-lo ao dar continuidade ao trabalho com a apostila. Ou seja, as mudanças ocorrem somente na teoria (documentos), já a prática perpetua-se, mesmo havendo mudanças na gestão, e inclusive se percebe que a mudança de coligação partidária não significa mudanças reais na condução de propostas para a educação pública.

Destacamos, ainda, no que concerne à PCEI, que os conteúdos presentes nela foram elaborados por um grupo de pessoas e, desse modo, consideramos que "[...] o sistema cultural e educacional é um elemento excepcionalmente importante na manutenção das relações existentes de dominação e exploração" (APPLE, 1989, p. 26). Isso se evidencia quando Gasparin (2012, p. 149-150) reitera:

A proposta de planejamento, dentro da perspectiva histórico crítica, deveria ser iniciada e realizada com base em problemas sociais existentes na comunidade e na sociedade. Todavia, essa linha de raciocínio e de trabalho torna-se inviável por causa da estrutura organizacional da maioria das escolas [...] Normalmente, os conteúdos são definidos antes do início do ano letivo [...] Assim, o planejamento inicia-se não pelos grandes problemas sociais, mas pela listagem dos conteúdos a serem trabalhados já determinados.

Desse modo, as escolas serão órgãos reprodutivos, à medida que "[...] ajudam a manter o privilégio por meios culturais, ao tomar a forma e o conteúdo da cultura e do conhecimento dos grupos poderosos e defini-los como um conhecimento legítimo a ser preservado e transmitido" (APPLE, 1989, p. 58).

Apesar de a PCEI (2011) discursar que a escola não pode se limitar a "oferecer noções dos diversos ramos do saber, nem tão pouco render-se a modismos", ao utilizar-se dos sistemas privados de ensino (apostilas) como meio educativo, contesta sua propositura, pois, com ele, incide-se o estreitamento curricular, uma vez que "[...] os sistemas apostilados de ensino são [...] uma compilação de informações mais importantes sobre cada disciplina, exercícios, gravuras, esquemas, etc." (ADRIÃO et al., 2015, p. 94), demonstrando a seletividade do que deve ser ensinado às crianças.

$\mathrm{Na}$ breve leitura que fizemos do material utilizado pelas crianças de três anos, pudemos verificar uma compilação com poucas informações, prioridade a exercícios manuais (desenhos) e pouco direcionamento para propostas mais práticas, que proponham experimentações com os mais diversos materiais, recursos e espaços. Lembramos que, "uma educação fragmentada não produz eco na alma de uma criança” (HADDAD, 2006, p. 540).

Cabe ressaltar que o uso de apostilas empobrece a articulação das

[...] experiências e [d]os saberes das crianças com os conhecimentos que fazem parte do patrimônio cultural, artístico, científico e tecnológico. Tais práticas são efetivadas por meio de relações sociais que as crianças desde bem pequenas estabelecem com os professores e as outras crianças, e afetam a construção de suas identidades (BRASIL, 2009a, p. 06). 
A Utilização de Sistemas Privados de Ensino na Educacão Pública

Consequentemente, o uso de apostilas inviabiliza a efetivação de um "[...] currículo sustentado nas relações, nas interações e em práticas educativas intencionalmente voltadas para as suas experiências cotidianas" (BRASIL, 2009a, p. 08).

Consideramos, ainda, que o uso de apostilas desencadeia o engessamento do trabalho docente, transformando o professor em um mero "aplicador ou reprodutor daquilo que foi pensado e elaborado por outros profissionais" (BRASIL, 2009b, p. 52).

Nesse ínterim, indagamos: as escolas não teriam autonomia suficiente para desenvolver suas próprias propostas curriculares? Em termos, sim, e eles são possíveis por meio do Projeto Político Pedagógico de cada unidade escolar; no entanto, não é isso que os PPP apresentam. As orientações descritas divergem do que se efetiva nas unidades escolares. Nota-se que em ambos os documentos, PCEI e PPP, não há referência ao uso ou apoio de material didático (apostilas) como proposição de trabalho com as crianças.

Pensando nas condições de idade e nas metodologias de trabalho com crianças pequenas, problematizamos: a que cabe, nesse processo, o uso do sistema apostilado na Educação Infantil? Isso também não deveria estar claro nos PPP? No entanto, não está. Em que cabe utilizar-se de meios escolarizados como forma de garantir aprendizado às crianças pequenas? Essas crianças necessitam de tais materiais para se desenvolver? Tussi (2011, p. 101-102) pondera que

[...] é recorrente, nos dias atuais, o currículo definido também pelo livro didático ou material didático, em que os profissionais da educação e Educação Infantil ancoram-se neles para a produção das suas aulas e práticas junto às crianças e estudantes, definindo dessa forma o currículo a ser trabalhado. Como assim, livro didático para a Educação Infantil? Pois bem, o livro ou material didático já fazem parte do cotidiano das creches e pré-escolas.

Dessa forma, o discurso proferido nos referidos documentos municipais deixa lacunas e evidencia a falta de uma discussão mais profunda sobre suas concepções de infância, de seu currículo, como de suas propostas pedagógicas. Essas discussões se fazem cada vez mais importantes, vistos os novos rumos com os quais a Educação Infantil tem se deparado no atual contexto das políticas.

É necessário que o discurso exposto nos documentos analisados atenda e execute, na prática, sua ação educativa alicerçada nas relações, nas interações que considerem as experiências cotidianas das crianças, caracterizando a Educação Infantil tal qual deve ser, não se limitando a práticas com distinções próprias do ensino fundamental.

As contradições averiguadas nos textos das legislações municipal, assim como na própria apostila, denotam o reflexo de uma sociedade regulada por preceitos neoliberais, que objetivam a privatização da Educação. A ação consciente e transformação social tão enfatizada na Proposta Curricular Municipal são ações que a política pública não faz questão de assegurar, promovendo cada vez mais a reprodução cultural da classe dominante.

\section{Referências}

ADRIÃO, Teresa et al. Sistemas de ensino privados na educação pública brasileira: consequências da mercantilização para o direito à educação. Relatório de Pesquisa. 2015. Disponível em: <http://flacso.org.br/files/2016/04/Peri-Sistemas-de-Ensino-Privado-naEduca\%C3\%A7\%C3\%A3o-P\%C3\%BAblica-Brasileira-ok.pdf>. Acesso em: 07 mar. 2018. 
A Utilização de Sistemas Privados de Ensino na Educação Pública

APPLE, Michael W. Educação e poder. Porto alegre: Artes Medicas, 1989.

BARBOSA, Maria C. S. Por amor e por força: rotinas na educação infantil. Porto Alegre: Artmed, 2001.

BETTI, Mauro; ZULIANI, Luiz R. Educação Física escolar: uma proposta de diretrizes pedagógicas. Revista Mackenzie de Educação Física e Esporte, São Paulo, Ano 1, n. 1, 2002. Disponível em: < http://www.ceap.br/material/MAT25102010170018.pdf>. Acesso em: 25 maio 2018.

BRASIL. Parecer CNE/CEB 020/2009. Resolução CNE/CEB n. 5/2009. Diretrizes Curriculares Nacionais para a Educação Infantil. Brasília, DF: Conselho Nacional de Educação; Câmara da Educação Básica, 2009a.

BRASIL. Projeto de Cooperação Técnica MEC e UFRGS para Construção de Orientações Curriculares para a Educação Infantil. Práticas Cotidianas na Educação Infantil: Bases para a Reflexão sobre as Orientações Curriculares. Brasília: MEC/UFRGS, 2009b.

CARIA, Alcir de S. Projeto Político Pedagógico: em busca de novos sentidos. São Paulo: Editora e Livraria Instituto Paulo Freire. Versão online. 2011. Série Educação Cidadã. Disponível em: <http://www.acervo.paulofreire.org:8080/jspui/bitstream/7891/3085/1/F PF_PTPF_12_082.pdf>. Acesso em: 13 maio 2018.

ENTRELINHAS para você!: infantil 3, aluno/ Equipe SEFE. Curitiba: SEFE, 2017.

FOCHI, Paulo S. A criança é feita de cem: as linguagens em Malaguzzi. In: FOCHI, Paulo S. Infância e educação infantil II: linguagens. São Leopoldo: Ed. Unisinos, 2014.

GADOTTI, Moacir. Pressupostos do projeto pedagógico. In: CONFERÊNCIA NACIONAL DE EDUCAÇÃO PARA TODOS, 1994, Brasília. Anais... Brasília, 1994.

GASPARIN, João Luiz. Um didática para a pedagogia histórico crítica. 5. ed. rev. Campinas; São Paulo: Autores Associados, 2012.

HADDAD, Lenira. Políticas Integradas de Educação e Cuidado Infantil: desafios, armadilhas e possibilidades. Cadernos de Pesquisa, São Paulo, v. 36, n. 129, p 519-546, set./dez. 2006.

IRATI. Projetos Político Pedagógicos dos Centros Municipais de Educação Infantil do município de Irati/PR. Irati, S. d.

IRATI. Proposta Curricular da Rede Municipal de Ensino de Irati: Educação Infantil. Irati, 2011.

SAVIANI, Dermeval. Escola e democracia: teorias da educação, curvatura da vara, onze teses sobre educação e política. São Paulo: Cortez; Autores Associados, 1989.

TUSSI, Dorcas. O espaço e o currículo: conexões e diálogos sobre as práticas pedagógicas no cotidiano da educação infantil. 2011. 175 f. Dissertação (Mestrado em Educação) Universidade Federal de Santa Maria, Santa Maria, 2011.

VEIGA, Ilma P. A. (Org.). Projeto político-pedagógico da escola: uma construção possível. 14. ed. São Paulo: Papirus, 2002.

VIGOTSKI, Lev S. A construção do pensamento e da linguagem. São Paulo: Martins Fontes, 2001. 
A Utilização de Sistemas Privados de Ensino na Educação Pública

Elisandra Aparecida Czekalski é mestranda em Educação - UNICENTRO/PR. Professora e Pedagoga em Educação Infantil na rede municipal de Irati/PR.

ORCID: http://orcid.org/0000-0002-4631-019X

E-mail: elisandra_czk@hotmail.com

Marisa Schneckenberg é doutora em Educação. Docente do Curso de Pedagogia e do Programa de Pós-Graduação em Educação - UNICENTRO/PR. Orientadora na linha de Pesquisa: Políticas Educacionais, história e organização da educação - PPGE/UNICENTRO. ORCID: http://orcid.org/0000-0002-4006-3001

E-mail: marisaunicentro@hotmail.com

Recebido em 17 de fevereiro de 2019 Aprovado em 18 de abril de 2019 


\section{Editores do volume 9}

José Marcelino de Rezende Pinto - Universidade de São Paulo, São Paulo/SP, Brasil

Nalú Farenzena - Universidade Federal do Rio Grande do Sul, Porto Alegre/RS, Brasil

\section{Comitê Editorial}

José Marcelino de Rezende Pinto - Universidade de São Paulo, Brasil

Juca Gil - Universidade Federal do Rio Grande do Sul, Brasil

Theresa Adrião - Universidade Estadual de Campinas, Brasil Ângelo

Ricardo de Souza - Universidade Federal do Paraná, Brasil

Márcia Aparecida Jacomini - Universidade Federal de São Paulo, Brasil

\section{Conselho Editorial}

\section{Alejandro Morduchowicz}

Universidad Pedagógica, Provincia de Buenos Aires, Argentina

Fernanda Saforcada

Universidade de Buenos Aires, Argentina

Jacques Velloso

Universidade de Brasília, Brasil

João Monlevade

Senado Federal, Brasil

Jorge Abrahão de Castro

Instituto de Pesquisa Econômica Aplicada / IPEA, Brasil

Juca Gil

Universidade Federal do Rio Grande do Sul, Brasil

Lisete Regina Gomes Arelaro

Universidade de São Paulo, Brasil

Luis Carlos Sales

Universidade Federal do Piauí, Brasil

Luiz de Sousa Junior

Universidade Federal da Paraíba, Brasil

Luiz Fernandes Dourado

Universidade Federal de Goiás, Brasil

Magna França

Universidade Federal do Rio Grande do Norte, Brasil

\section{Maria Beatriz Luce}

Universidade Federal do Pampa, Brasil

Universidade Federal do Rio Grande do Sul, Brasil

Marcos Edgar Bassi

Universidade Federal de Santa Catarina, Brasil

\author{
Maria Dilnéia Espíndola Fernandes \\ Universidade Federal de Mato Grosso do Sul, Brasil \\ Nalú Farenzena \\ Universidade Federal do Rio Grande do Sul, Brasil \\ Nelson Cardoso do Amaral \\ Universidade Federal de Goiás, Brasil \\ Nicholas Davies \\ Universidade Federal Fluminense, Brasil \\ Rosana Evangelista Cruz \\ Universidade Federal do Piauí, Brasil \\ Rosana Gemaque \\ Universidade Federal do Pará, Brasil \\ Robert E. Verhine \\ Universidade Federal da Bahia, Brasil \\ Romualdo Portela de Oliveira \\ Universidade de São Paulo, Brasil \\ Theresa Adrião \\ Universidade Estadual de Campinas, Brasil \\ Tristan McCowan \\ University of London, Reino Unido \\ Vera Jacob \\ Universidade Federal do Pará, Brasil \\ Vera Peroni \\ Universidade Federal do Rio Grande do Sul, Brasil \\ Vitor Henrique Paro \\ Universidade de São Paulo, Brasil
}

\section{Equipe editorial}

Apoio ao Comitê Editorial: Patrícia Balthazar Garcia

Diagramação, Revisão de português e normalização: Edson Leonel de Oliveira

Revisão de inglês: Ananyr Porto Fajardo 